\title{
Organize Surfaktant Yapılar Varlığında Floresin ve Safranin-T Arasındaki Enerji Transferi
}

\author{
Ebru BOZKURT ${ }^{1}$
}

ÖZET: Bu çalışmada, Floresin ve Safranin-T molekülleri arasındaki enerji transferi ters misel ve mikro-emülsiyon sistemlerde UV-Gör. absorpsiyon, durgun-hal ve zamana-bağlı floresans spektroskopisi teknikleri kullanılarak incelenmiştir. Su, ters misel ve mikro-emülsiyon çözeltileri içerisindeki enerji transfer parametreleri hesaplanmıştır. Floresin ve Safranin-T molekülleri arasındaki enerji transferinin yüksek verimde meydana geldiği ve enerji transfer parametrelerinin ortamın boyutu değiştirilerek kontrol edilebileceği gözlenmiştir.

Anahtar Kelimeler: Floresans rezonans enerji transferi (FRET), Floresin, Förster mesafesi, Safranin-T, Ters misel.

\section{Energy Transfer between Fluoresin and Safranin-T in the Presence of Organized Surfactant Structures*}

\begin{abstract}
In this study, energy transfer between Fluorescein and Safranine T molecules were investigated by using UV-Vis absorption, steady-state and time-resolved fluorescence spectroscopy techniques in reverse micelle and microemülsion systems. The energy transfer parameters were calculated in water, reverse micelle and microemülsion solution. It was observed that energy transfer between Fluorescein and Safranine T molecules occurs at high efficiency and the energy transfer parameters can be controlled by changing the size of the media.
\end{abstract}

Keywords: Fluorescence resonance energy transfer (FRET), Fluorescein, Förster distance, Reverse micelle, Safranine-T.

\footnotetext{
1 Ebru BOZKURT (0000-0002-5345-9718), Atatürk Üniversitesi, Erzurum Meslek Yüksekokulu, Mülkiyet Koruma ve Güvenlik Bölümü, Erzurum, Türkiye.

Sorumlu yazar/Corresponding Author: Ebru BOZKURT, ebrubozkurt@ atauni.edu.tr

Bu makale 26-28 October 2016 tarihinde Adana'da 1st International Mediterranean Science and Engineering Congress'de sunulmuştur.
} 


\section{Giriș}

Elektron, proton ve enerji transfer olayları molekül içi ve moleküller arasında meydana gelen en önemli olaylardır. Floresans Rezonans Enerji Transferi (FRET), bir molekülden (donör=D) diğer moleküle (akseptör=A) enerjinin 1şımasız olarak transfer edildiği fizikokimyasal bir prosestir (Chatterjee et al. 2005). FRET mekanizması Förster Teorisi ile açıklanabilir (Seth et al. 2005). Förster FRET'in, donör-akseptör çiftinin bazı spektroskopik ve geometrik özelliklerine bağlı olan uzun mesafeli dipol-dipol rezonans etkileşimi ile meydana geldiğini önermiştir (De and Girigoswami 2004). Bu teoriye göre, enerji transferinin meydana gelmesi; donör molekülünün emisyon spektrumu ile akseptör molekülünün absorpsiyon spektrumları arasındaki spektral çakışma alanına, donörün kuantum verimine, donör ve akseptör moleküllerinin geçiş dipol momentlerinin relatif yönlenmesine ve donör ve akseptör moleküllerinin geçiş dipol momentleri arasındaki mesafeye bağlıdır (Chatterjee et al., 2005; Wang et al. 2015). Ayrıca enerji transfer etkinliği, donörakseptör arasındaki mesafenin 1/6. kuvvetiyle orantıl1 olarak değişir (Das et al. 2011; Ohta et al. 2016). Enerji transfer etkinliğinin mesafeye bağ lılığı, ̊̊ ölçeğindeki mesafeleri belirlemek için oldukça avantajlıdır (Hillisch et al. 2001). FRET, fotosensitizasyon ve fotosentez gibi enerji dönüşüm olayları (Sundström et al. 1999), DNA yapısının aydınlatılması (Clegg, 1992), iyon sensör teknolojisi gibi birçok alanda kullanılmaktadır (Chen et al. 2016; Dey et al. 2014).

Ters miseller, polar ve apolar çözücülerde uygun surfaktant molekülünün çözünmesiyle oluşan düzenli agregatlardır (Şekil 1). Bu sistemlerde polar çözücü olarak saf su, surfaktant olarak ise dioktil sülfosüksinat sodyum tuzu (AOT) sıkça kullanılır (Eskici and Axelsen 2016; Ghosh et al. 2017). Ters misel sistemlerde, oluşan nano ölçekteki su havuzlarının boyutu $\mathrm{W}_{0}$ (suyun surfaktanta molar oran1) parametresi ile karakterize edilir (Chowdhary and Ladanyi 2009). $\mathrm{W}_{0}$ değeri 15 'ten küçük olan sistemler ters misel, $\mathrm{W}_{0} \geq 15$ olan sistemler ise mikro-emülsiyon olarak adlandırılırlar (Pileni, 1993). Ters miseller, nano partikül sentezi (Eastoe et al. 2006; Quinlan et al. 2000), ilaç tasarımı (MüllerGoymann, 2004), tekstil endüstrisi (Wang et al. 2016) ve biyomoleküllerin saflaştırılması (Mathew and Juang 2007) gibi birçok alanda kullanılmaktadır. Ayrıca, floresan boya bileşiklerinin foto-fiziksel özellikleri de bu sistemlerde incelenmektedir (Hazra and Sarkar 2001).

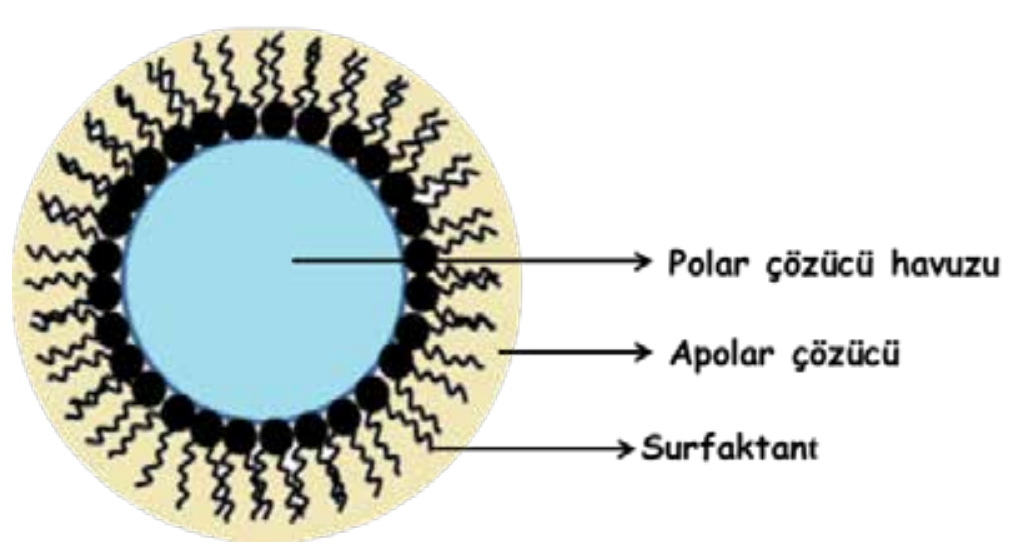

Şekil 1. Ters misel sistemlerin yapısı

$\mathrm{Bu}$ çalışmada, Floresin (FL) ve Safranin-T (ST) arasındaki enerji transferinin ters misel ortamlarda incelenmesi amaçlanmıştır. Bu amaçla, FL-ST için saf su ve farklı $\mathrm{W}_{0}$ değerlerine sahip ters misel ortamlarda UV-Gör. absorpsiyon, durgunhal ve zamana-bağlı floresans ölçümleri alınması planlanmıştır. Tüm çözelti sistemleri için FRET parametreleri hesaplanması düşünülmüştür. $\mathrm{Bu}$ çalışmanın sonuçları ile FRET temelli yeni bir sistem elde edilmiş olacaktır. Ters miseller kullanılarak FRET parametrelerinin kontrol edilebilmesi enerji transferinin kullanıldığ alanındaki birçok çalışmaya 1şık tutacaktır (Rabouw et al. 2014; Shi et al. 2015). 


\section{MATERYAL VE YÖNTEM}

\section{Materyaller}

3,7-diamino-2,8-dimetil-5-fenilfenazinyum klorür (Safranin-T) ve n-heptan (apolar çözücü olarak) Merck, 3',6'-dihidroksispiro[izobenzofuran-1(3H),9'[9H]ksanten]-3-on (Floresin), dioktil sülfosüksinat sodyum tuzu (AOT) ve diğer kimyasallar ise Sigma

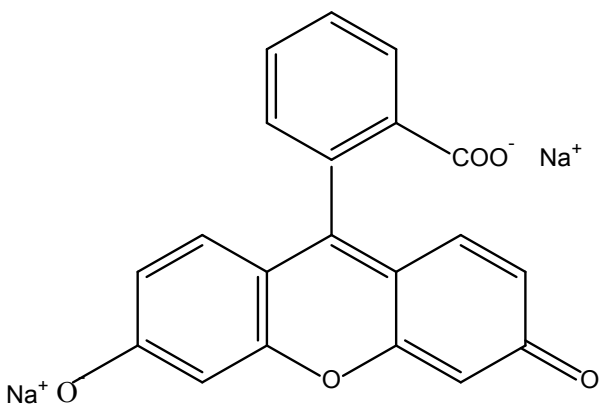

(a) firmalarından temin edilmiştir. FL ve ST'nin $1 \times 10^{-}$ ${ }^{3}$ M'lık stok çözeltileri sırasıyla etanol ve metanol içerisinde hazırlanmıştır. Su, ters misel ve mikroemülsiyon çözeltilerindeki probların istenen konsantrasyondaki numuneleri, bu stok çözeltilerden çözücünün buharlaştırılmasıyla hazırlanmıştır. Çalışmada kullanılan boyar maddelerin moleküler yapıları Şekil 2.' de verilmiştir.<smiles>Cc1cc2nc3cc(C)c(N)cc3[n+](-c3ccccc3)c2cc1N</smiles>

(b)

Şekil 2. Moleküler yapıları (a) Floresin (FL) ve (b) Safranin-T (ST)

\section{Ters Misellerin Hazırlanması}

Ters misel çözeltileri sodyum bis(2-etilhekzil) sülfosüksinat (AOT), n-heptan ve saf su kullanılarak, saf suyun surfaktanta molar oranını veren $\mathrm{W}_{0}$ parametresine bağlı olarak hazırlanmıştır. $\mathrm{Bu}$ amaçla önce $40 \mathrm{ml} \mathrm{n}$-heptan içerisinde AOT çözülmüsş, daha sonra istenen $\mathrm{W}_{0}$ değerinde ters miselleri elde etmek için gerekli miktardaki saf su eklenmiştir. Bütün ters misel ve mikro-emülsiyonlar için AOT 0,09 M olarak alınmıştır (Hazra and Sarkar 2001). Tüm ölçümler için FL ve ST konsantrasyonları sirasiyla $20 \mu \mathrm{M}$ ve $6 \mu \mathrm{M}$ olarak ayarlanmıştır ve tüm ölçümler oda sıcaklığında kaydedilmiştir.

\section{Cihazlar}

Tüm numunelerin UV-Gör. absorpsiyon ve floresans spektrumları sirasıyla Perkin Elmer
Lambda 35 UV/VIS spektrofotometre ve Shimadzu RF-5301PC spektroflorometre ile kaydedilmiştir. Durgun-hal floresans ölçümleri için numuneler 400 nm'de uyarılmış ve floresans şiddetleri 410-700 $\mathrm{nm}$ dalgaboyu aralığında kaydedilmiştir. Floresans yaşam ömrü ve durgun-hal anizotropi ölçümleri, Photon Technology International (PTI) firmasindan LaserStrobe Model TM3 spektroflorofotometre ile gerçekleştirilmiştir. Cihazın uyarma kaynağı pulse azot lazeri/ayarlanabilir boya lazeri kombinasyonu olup, FL boya bileşiğinin durulma eğrileri $\left(\lambda_{\text {exc }}=\right.$ $457 \mathrm{~nm}$ ) aritmetik progresyona göre zaman artışı ile doğrusal olmayan bir zaman ölçeği kullanarak 200 kanal üzerinden toplanmıştır. Floresans durulmaları, cihazın yaşam ömrü dağılım analizi yazılımı ile analiz edilmiştir (Bozkurt et al. 2012).

Floresans kuantum verimleri $(\Phi)$ Parker-Rees metoduyla belirlenmiştir. Parker-Rees denklemi;

$$
\emptyset_{s}=\emptyset_{r}\left(\frac{D_{s}}{D_{r}}\right)\left(\frac{\eta_{s}^{2}}{\eta_{r}^{2}}\right)\left(\frac{1-10^{-O D_{r}}}{1-10^{-O D_{s}}}\right)
$$


şeklinde verilip, burada $\Phi_{\mathrm{s}}$ ve $\Phi_{\mathrm{r}}$ sırasıyla, numune ve referansin floresans kuantum verimi; $D_{s}$ ve $D_{r}$, sırasıyla numune ve referansın düzeltilmiş floresans spektrumu altındaki alanları; $\eta_{\mathrm{s}}$ ve $\eta_{\mathrm{r}}$ sirasiyla numune ve referansın çözücüsünün kırılma indisi; $\mathrm{OD}_{\mathrm{s}}$ ve $\mathrm{OD}_{\mathrm{r}}$, sırasıyla numune ve referansın uyarılma dalga boyunda $\left(\lambda_{\text {exc }}=400 \mathrm{~nm}\right.$ ) ölçülen optik yoğunluğudur (Tan et al. 2014). Referans olarak floresin bileşiğinin $0,1 \mathrm{M} \mathrm{NaOH}$ içerisindeki çözeltisi kullanılmıştır. Floresin bileşiğinin $0,1 \mathrm{M} \mathrm{NaOH}$ içerisinde $496 \mathrm{~nm}$ uyarma dalgaboyundaki kuantum verimi 0,95 $\pm 0,03$ 'tür (Brouwer, 2011). $\mathrm{Bu}$ değer için verilen uyarma dalgaboyu $(496 \mathrm{~nm})$

$$
\mathrm{k}_{\mathrm{ET}}=\frac{1}{\tau_{\mathrm{D}}}\left(\frac{R_{0}}{r}\right)^{6}
$$

eşitliği ile verilir. Burada, $\tau_{\mathrm{D}}$ akseptör bulunmadığı durumda donörün yaşam ömrü, $r$ donör-akseptör arasındaki mesafe ve $R_{0}$ Förster mesafesini ifade

$$
R_{0}=0.211\left[\kappa^{2} \eta^{-4} Q_{D} J(\lambda)\right]^{1 / 6}
$$

Bu eşitlikte; $Q_{D}$ akseptörün bulunmadığg durumda donörün kuantum verimi, $\eta$ ortamın kırılma indisi ve $\kappa^{2}$ ise yönlendirme faktörüdür. $\mathrm{Bu}$ faktör, donörün ve akseptörün geçiş dipollerinin uzaydaki relatif yönelimini tarif eder ve genellikle donör ve akseptörün

$J(\lambda)=\frac{\int_{0}^{\infty} F_{D}(\lambda) \varepsilon_{A}(\lambda) \lambda^{4} d \lambda}{\int_{0}^{\infty} F_{D}(\lambda) d \lambda}$

eşitliği ile verilir. $F_{D}(\lambda)$ akseptörün bulunmadığ durumda donörün normalize floresans şiddeti ve $\varepsilon_{\mathrm{A}}(\lambda)$ ise akseptörün molar absorptivite katsayıdır. Önemli FRET parametrelerinden biri olan enerji transfer çalışmada kullanılan uyarma dalga boyundan farklı olsa dahi referans bileşiklerin kuantum verimleri çoğunlukla uyarma dalga boyundan bağımsızdır. Kuantum verimi hesaplamak için kullanılan referans bileşik numune ile aynı dalga boyunda uyarılmalıdır. Böylece farklı uyarma dalgaboylarından kaynaklanan şiddet farklılıklarının düzeltilmesine ihtiyaç kalmamaktadır (Lakowicz, 2013).

\section{FRET Parametrelerinin Hesaplanması}

Förster Teorisi'ne göre floresans rezonans enerji transfer hızı $\left(\mathrm{k}_{\mathrm{ET}}\right)$;

etmektedir. $\mathrm{R}_{0}$, enerji transferinin \%50'sinin meydana geldiği anda donör-akseptör arasındaki mesafe olup bu değer aşă̆ıdaki eşitlik kullanılarak hesaplanabilir.

spektral örtüşme integrali $(\mathrm{J}(\lambda))$ için en uygun ortalama dinamik dağ 1 lımın olduğu değer olan $2 / 3$ olarak kabul edilir. Spektral örtüşme integrali, donörün emisyon spektrumu ve akseptörün absorpsiyon spektrumu arasındaki spektral örtüşme derecesini temsil eder ve

$$
\mathrm{E}=1-\frac{F_{D A}}{F_{D}}=1-\frac{\tau_{\mathrm{DA}}}{\tau_{\mathrm{D}}}
$$


Gelen 1ş1k şiddeti sabit olduğunda ölçülen anizotropi durgun-hal anizotropi (r) olarak adlandırılır. $\mathrm{I}_{\mathrm{VV}}$; hem uyarma hem de emisyon polarizerlerinin elektrik alan vektörünün düzleme dik, $\mathrm{I}_{\mathrm{VH}}$; ise uyarma polarizerinin elektrik alan $\mathrm{r}=\frac{\mathrm{I}_{\mathrm{VV}}-\mathrm{GI}_{\mathrm{VH}}}{\mathrm{IVV}_{\mathrm{V}}+2 \mathrm{GI}_{\mathrm{VH}}}$

Burada G, düzeltme faktörü olup;

$$
G=\frac{I_{H V}}{I_{H H}}
$$

şeklinde ifade edilir.

\section{BULGULAR VE TARTIŞMA}

$\mathrm{Bu}$ çalışmada, donör molekülü olarak Floresin (FL) ve akseptör molekülü olarak Safranin-T (ST) kullanılmıştır. Donör (FL) ve akseptör (ST) için vektörünün düzleme dik ve emisyon polarizerinin elektrik alan vektörünün düzleme yatay olduğu durumdaki floresans şiddetleri olmak üzere durgun-hal anizotropisi (6) eşitliği ile hesaplanır (Lakowicz, 2013). uygun konsantrasyonlar belirlendikten sonra enerji transferinin meydana gelebilmesi için var olması gereken spektral örtüşme alanları FL-ST çifti için tüm çalışılan ortamlarda belirlenmiştir (Şekil 3).
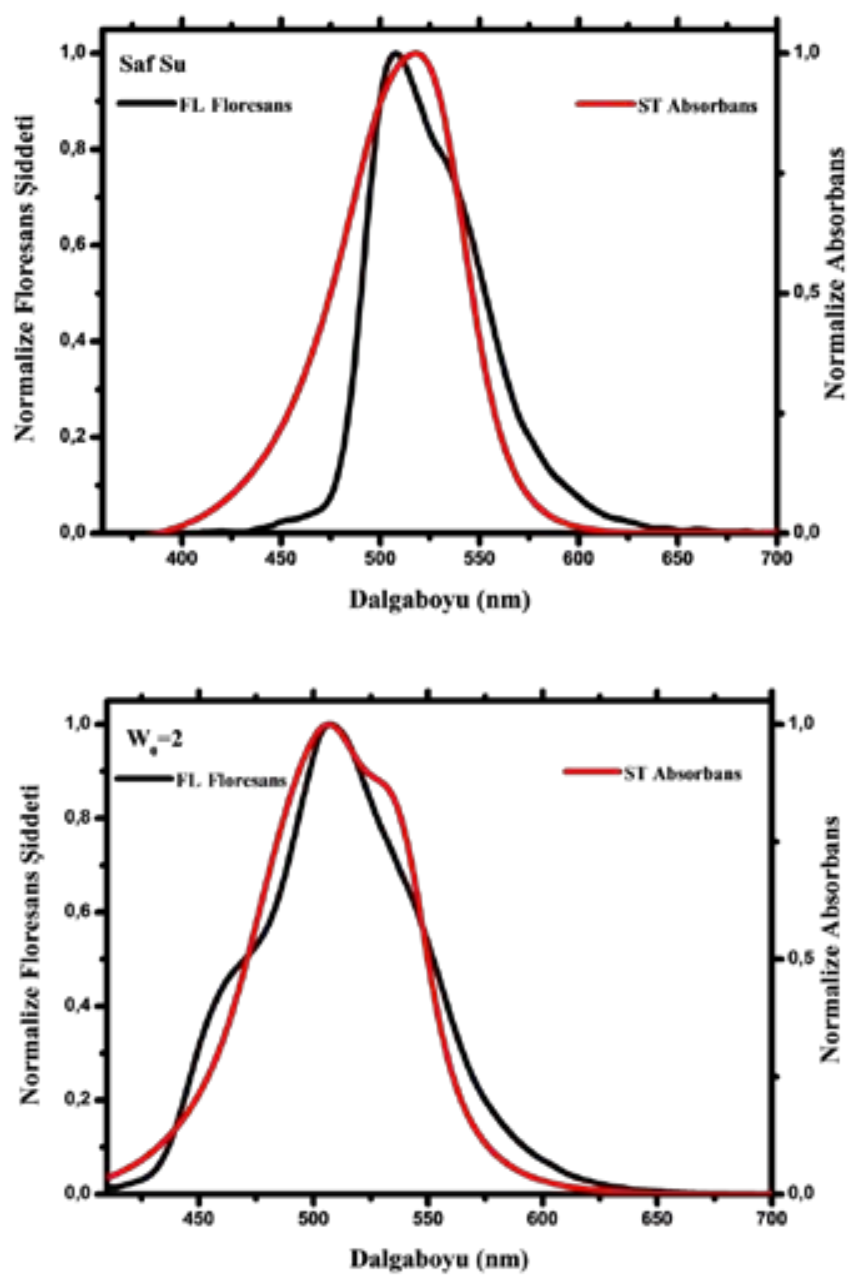

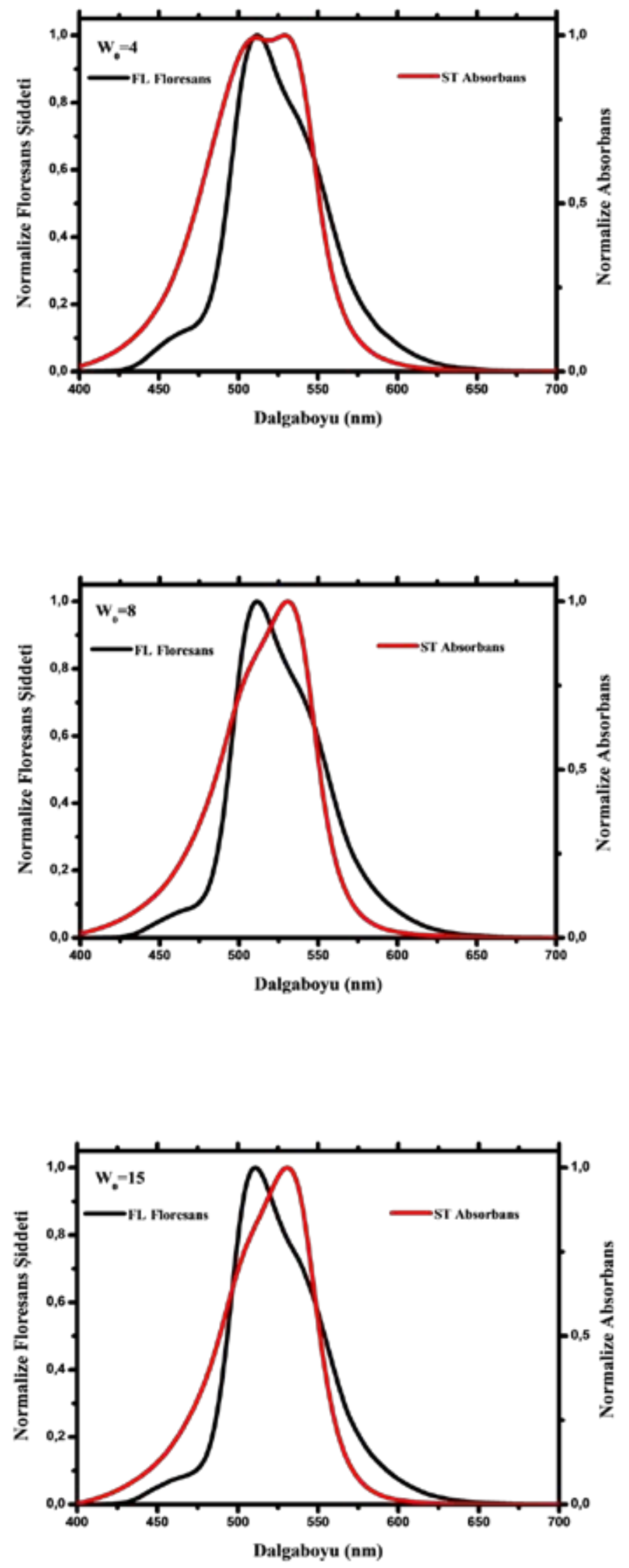

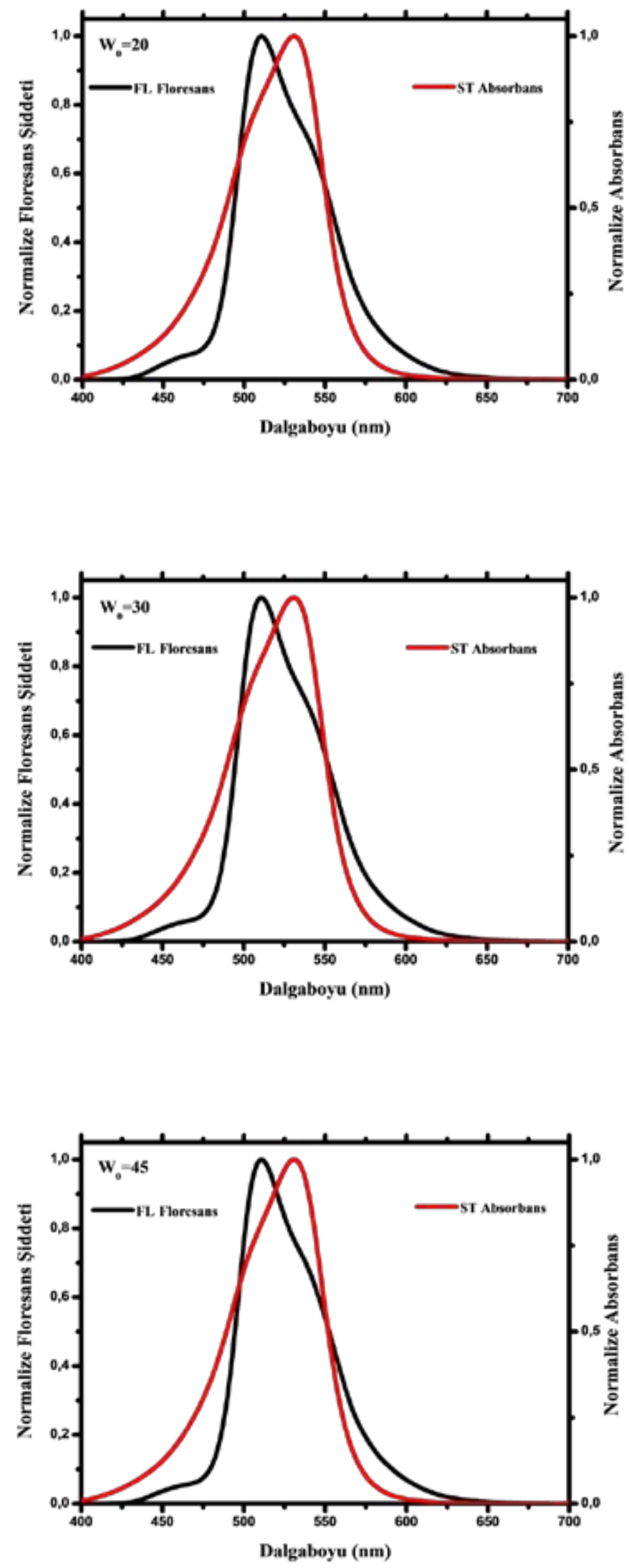

Şekil 3. FL-ST çifti için saf su ve farklı $\mathrm{W}_{0}$ değerine sahip ters misel ve mikro-emülsiyon ortamlardaki spektral örtüşme alanları 
İki molekülün emisyon ve absorpsiyon spektrumlarının örtüştüğü belirlendikten sonra bu moleküller arasında enerji transferinin varlığını kanıtlamak için donörün uyarma dalga boyunda $\left(\lambda_{\text {exc }}=400 \mathrm{~nm}\right)$ FL ve ST moleküllerinin ayrı ayrı ve FL-ST çiftinin birlikte floresans ölçümleri alınmıştır. Şekil 4a'da görüldüğü gibi donörün uyarma dalga boyunda FL-ST çifti için alınan spektrumda 449 ve $566 \mathrm{~nm}$ dalgaboylarında iki pikin varlığ 1 belirlenmiştir. $449 \mathrm{~nm}$ 'deki floresans pik şiddetinin saf FL'nin pik şiddetine kıyasla daha düşük, 566 nm'deki floresans pik şiddetinin ise saf ST'nin pik şiddetine kıyasla daha büyük olduğu gözlenmiştir. Aynı sonuçlar ters misel sistemlerde alınan ölçümlerde de gözlenmiştir (Şekil 4b). Bu durum iki molekül arasında bir enerji transferinin varlığını kanıtlamaktadır (Bozkurt et al. 2015; Lee et al. 2015).
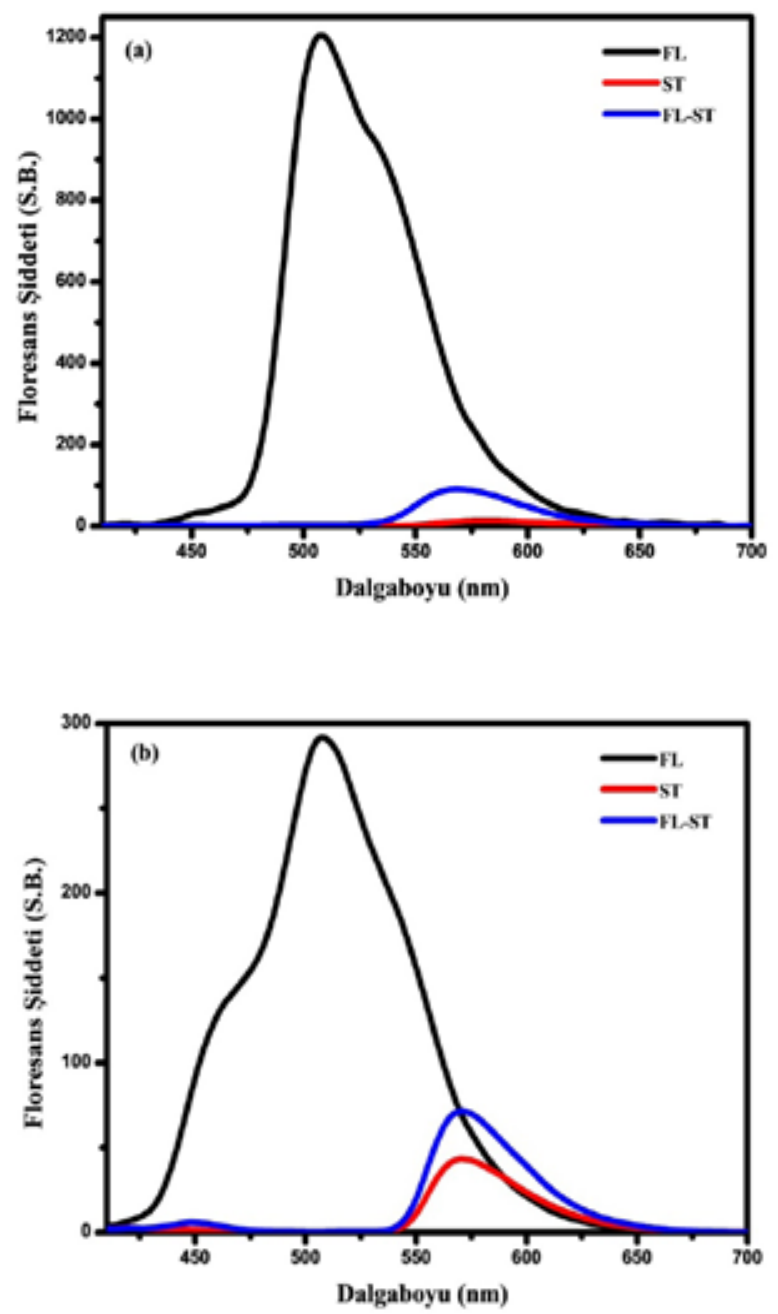

Şekil 4. FL, ST ve FL-ST çifti için (a) saf su ve (b) ters misel ortamlardaki floresans spektrumları $\left(\lambda_{\text {exc }}=400 \mathrm{~nm}\right)$

$\mathrm{Bu}$ sonuçlar 1şı̆̆ında enerji transferinin varlı̆̆ 1 kanıtlandıktan sonra iki molekül arasındaki enerji transferine ters misel ve mikro-emülsiyon ortamların etkisi incelenmiştir. Farklı $\mathrm{W}_{0}$ (2-45) değerine sahip ters miseller içerisinde FL-ST çifti için alınan floresans spektrumları Şekil 5a'da verilmiştir. Şekil 5 b ve $5 c^{\prime}$ de görüldüğü gibi su havuzu boyutları $\mathrm{W}_{0}=2^{\prime}$ den $\mathrm{W}_{0}=45^{\prime} \mathrm{e}$ değiştirildikçe, hem donörün hem de akseptörün floresan maksimumlarında kırmızıya kayma ve akseptörün pik şiddetinde bir artış meydana geldiği belirlenmiştir. Floresans spektrumlarında gözlemlenen bu kaymalar, ters misel ve mikro-emülsiyon ortamlarındaki boyaların etrafındaki mikro çevrenin saf sudaki koşullarından farklı olduğunu göstermektedir (De and Girigoswami 2004). 

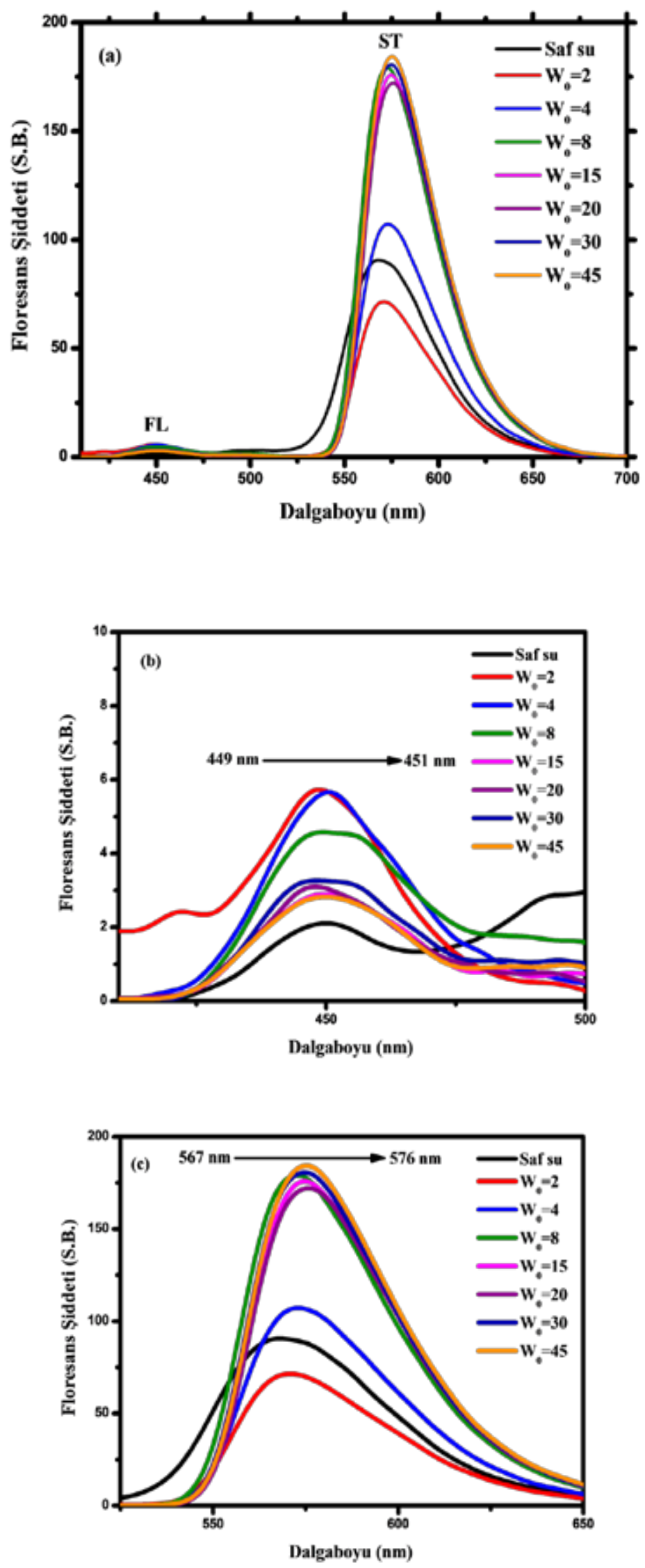

Şekil 5. (a) FL-ST çifti (b) FL ve (c) ST için saf su, farklı ters misel ve mikro-emülsiyon ortamlardaki floresans spektrumları 
Farklı ters misel ve mikro-emülsiyon ortamlarda FL ve ST arasındaki enerji transferi spektral olarak belirlendikten sonra, FRET için önemli olan parametreler (2), (3), (4) ve (5) eşitlikleri yardımıyla hesaplanmıştır. Çizelge 1'de FL-ST çifti için farklı ortamlarda hesaplanan çeşitli FRET parametreleri verilmiştir.

Çizelge 1. FL-ST çifti için saf su ve farklı $\mathrm{W}_{0}$ değerine sahip ters misel ve mikro-emülsiyon ortamlardaki FRET parametreleri

\begin{tabular}{cccccccc}
\hline Ortam & $\boldsymbol{\Phi}_{\mathbf{D}}$ & $\begin{array}{c}\mathbf{J x 1 0}^{\mathbf{1 6}} \\
\left(\mathbf{M}^{-\mathbf{1}} \mathbf{c m}^{-1} \mathbf{n m}^{\mathbf{4}}\right)\end{array}$ & $\begin{array}{c}\mathbf{R}_{\mathbf{0}} \\
(\mathbf{n m})\end{array}$ & $\begin{array}{c}\mathbf{r} \\
(\mathbf{n m})\end{array}$ & $\begin{array}{c}\mathbf{k}_{\mathbf{E T}} \mathbf{x 1 0} \\
\left(\mathbf{s}^{-\mathbf{1}}\right)\end{array}$ & $\mathbf{E}^{*}$ & $\mathbf{E}^{* *}$ \\
\hline Saf su & $\mathbf{0 . 6 5}$ & 3.48 & 8.65 & 3.27 & 6.16 & 1.00 & 0.38 \\
$\mathbf{W}_{\mathbf{0}}=\mathbf{2}$ & $\mathbf{0 . 7 8}$ & 3.04 & 8.72 & 4.68 & 0.94 & 0.98 & 0.02 \\
$\mathbf{W}_{\mathbf{0}}=\mathbf{4}$ & $\mathbf{0 . 7 4}$ & 3.49 & 8.60 & 4.08 & 2.08 & 0.99 & 0.05 \\
$\mathbf{W}_{\mathbf{0}}=\mathbf{8}$ & 0.87 & 3.46 & 8.82 & 3.86 & 3.52 & 0.99 & 0.06 \\
$\mathbf{W}_{\mathbf{0}}=\mathbf{1 5}$ & 0.85 & 3.56 & 8.83 & 3.56 & 5.69 & 1.00 & 0.12 \\
$\mathbf{W}_{\mathbf{0}}=\mathbf{2 0}$ & 0.89 & 3.59 & 8.92 & 3.59 & 5.77 & 1.00 & 0.17 \\
$\mathbf{W}_{\mathbf{0}}=\mathbf{3 0}$ & $\mathbf{0 . 8 9}$ & 3.60 & 8.93 & 3.60 & 5.69 & 1.00 & 0.16 \\
$\mathbf{W}_{\mathbf{0}}=\mathbf{4 5}$ & 0.84 & 3.63 & 8.86 & 3.45 & 7.37 & 1.00 & 0.21 \\
\hline
\end{tabular}

Durgun-hal ölçümlcrinden; $\mathrm{E}=1-\mathrm{F}_{\mathrm{DN}} / \mathrm{F}_{\mathrm{D}}$

"* Zamana-bağlı ölçümlerden; $\mathrm{E}=1-\tau_{\mathrm{D} N} / \tau_{\mathrm{D}}$ eşitlikleri kullanılarak hesaplanmıştır.

Çizelge 1'de görüldüğü gibi saf su ortamında spektral örtüşme integrali $\mathrm{J}(\lambda)=3,48 \times 10^{16} \mathrm{M}^{-1} \mathrm{~cm}$ ${ }^{1} \mathrm{~nm}^{4}$, Förster mesafesi $\mathrm{R}_{0}=8,65 \mathrm{~nm}$ ve donörakseptör arasındaki mesafe $\mathrm{r}=3,27 \mathrm{~nm}$ bulunmuştur. Ters misel ve mikro-emülsiyon ortamlarda $\mathrm{W}_{0}$ değeri arttıkça, bu değerlerin saf sudaki değerlere kıyasla daha büyük olduğu görülmüştür. Ters misel ve mikroemülsiyon ortamlarda $\mathrm{R}_{0}$ değerlerinin saf sudakine kıyasla büyük olması, çalışılan sistemlerdeki floresans enerji transferinin uzun mesafeli dipol-dipol etkileşimlerinden kaynaklandığını göstermektedir. Bununla birlikte saf suda donör-akseptör arasındaki mesafe (r) ters misel ve mikro-emülsiyon ortamlardaki değerlerden daha küçük olmasına rağmen enerji transfer etkinliğinin (E) bu ortamlarda saf suya yakın hatta aynı çıkması spektral örtüşme alanlarının büyüklüğünden kaynaklanmaktadır
(Aydın et al. 2009). Ayrıca E değerlerinin FL ve ST çifti için, misellerde ve lipozomlarda yapılan daha önceki çalışmalara kıyasla önemli ölçüde yüksek olduğu gözlenmiştir (Bozkurt et al. 2013; Chatterjee et al. 2005). Negatif yüklü surfaktant (AOT) ile pozitif yüklü akseptör molekülü (ST) arasındaki elektrostatik etkileşimlerden dolayı ters miseller ve mikro-emülsiyonlarda ST molekülünün çözünürlüğg̈u artmaktadır. Bu yüzden ST molekülü polar çözücü/ surfaktant ara yüzeylerine yakın bölgelerde lokalize olmaktadır. $\quad \mathrm{W}_{0}$ değeri değiştirilerek probun lokalizasyonu değiştirilebilmekte ve böylece enerji transfer etkinliği kontrol edilebilmektedir (Şekil 6). Ayrıca donör-akseptör arasındaki mesafe (r) arttıkça enerji transfer hızı azalmaktadır. Saf sudaki enerji transfer hızı $\left(\mathrm{k}_{\mathrm{ET}}\right)$ oldukça yüksek olup $\mathrm{W}_{0}$ değeri arttıkça ters misel içerisindeki su bileşimi arttığından 
$\mathrm{k}_{\mathrm{ET}}$ değeri saf sudaki değere yaklaşmaktadır. Bununla birlikte değişen su bileşimine bağlı olarak donör ve akseptörün floresans spektrumlarında gözlenen kaymaların ortam polaritesinin farklılığından kaynaklandığı belirlenmiş olup, bu farklılıklardan dolayı su ve diğer ortamlarda enerji transfer hızlarında da farklılıklar olduğu gözlenmiştir (Seth et al.2005).

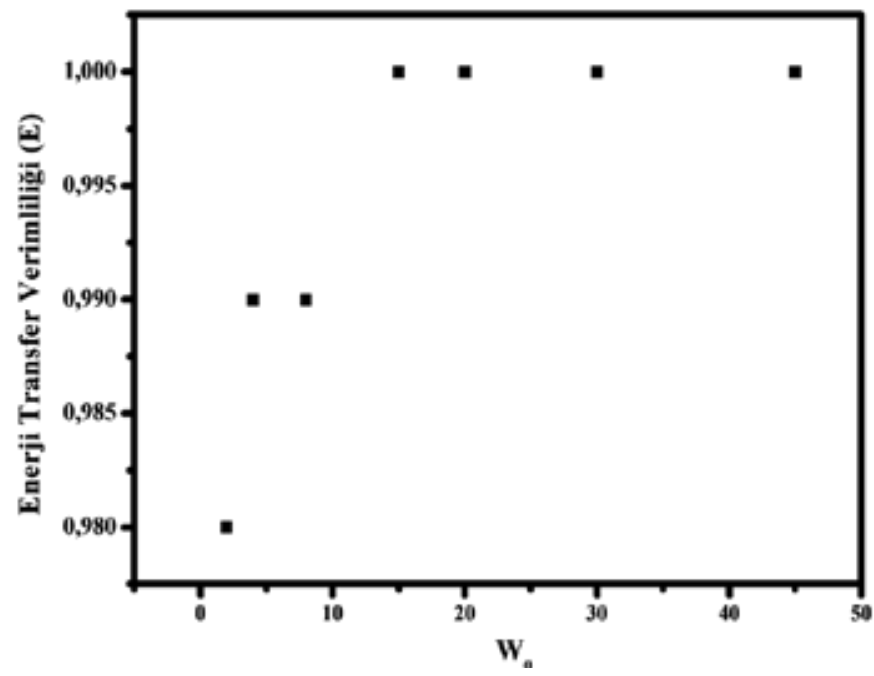

Şekil 6. Enerji transfer verimliliğinin (E), $\mathrm{W}_{0}$ değerine bağlı olarak değgisimi

FL-ST çifti için, enerji transfer hız sabitlerini ve enerji transfer etkinliğini belirlemek amaciyla durgunhal ölçümlerinin yanı sıra hem saf su hem de ters misel yapılar içerisinde zamana-bağlı floresans ölçümleri de yapılmıştır. Donör molekülünün (FL) saf su ve farklı $\mathrm{W}_{0}$ değerine sahip ters misel ve mikro-emülsiyon ortamlardaki floresans durulma eğrileri Şekil 7'de verilmiştir.

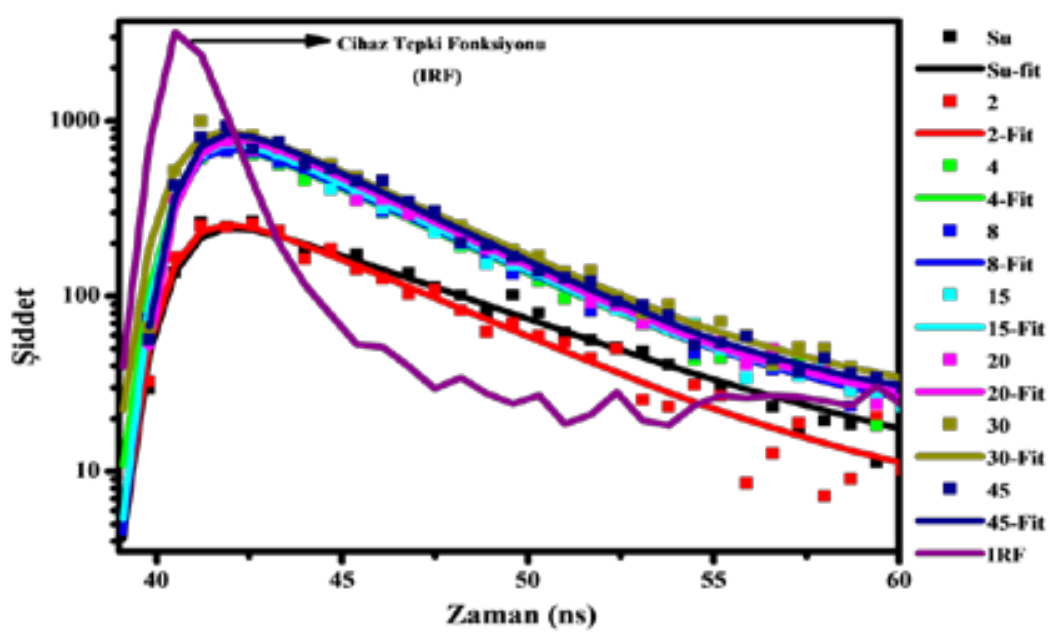

Şekil 7. FL için saf su ve farklı $\mathrm{W}_{0}$ değerine sahip ters misel ve mikro-emülsiyon ortamlardaki floresans durulma eğrileri

Ortama akseptör molekülü (ST) eklendiğinde FL'in yaşam ömrü değerlerinin azaldığı Çizelge 2'de açıkça görülmektedir. Ayrıca, zamana-bağlı ölçüm verilerinden hesaplanan enerji transfer etkinliği değerlerinin, durgunhal hesaplamalarında görülen trende sahip olduğu belirlenmiş̧ir (Çizelge 1). Ancak FL'nin yaşam ömrü değerlerinin single-eksponansiyel olmasından dolayı bu parametrenin durgun-hal verilerinden hesaplanmasının daha iyi olacağı bilinmektedir (Seth et al. 2005). 
Çizelge 2. Saf su ve farklı $\mathrm{W}_{0}$ değerine sahip ters misel ve mikro-emülsiyon ortamlarda FL için ST'nin varlığında $\left(\tau_{\mathrm{DA}}\right)$ ve yokluğunda $\left(\tau_{\mathrm{D}}\right)$ floresans yaşam ömrü ve anizotropi (r) değerleri

\begin{tabular}{cccc}
\hline Ortam & $\boldsymbol{\tau}_{\mathrm{D}}$ & $\boldsymbol{\tau}_{\mathrm{DA}}$ & $\mathbf{r}$ \\
\hline $\mathbf{W}_{\mathbf{0}}=\mathbf{2}$ & 4.438 & 4.349 & 1.00 \\
$\mathbf{W}_{\mathbf{0}}=\mathbf{4}$ & 4.229 & 4.013 & 1.00 \\
$\mathbf{W}_{\mathbf{0}}=\mathbf{8}$ & 4.053 & 3.820 & 0.25 \\
$\mathbf{W}_{\mathbf{0}}=\mathbf{1 5}$ & 4.094 & 3.610 & 0.11 \\
$\mathbf{W}_{\mathbf{0}}=\mathbf{2 0}$ & 4.051 & 3.369 & 0.10 \\
$\mathbf{W}_{\mathbf{0}}=\mathbf{3 0}$ & 4.096 & 3.438 & 0.10 \\
$\mathbf{W}_{\mathbf{0}}=\mathbf{4 5}$ & 3.962 & 3.113 & 0.09 \\
Saf su & 5.596 & 3.469 & $-\mathbf{0 . 1 6}$ \\
\hline
\end{tabular}

Donörün $(20 \mu \mathrm{M}$ FL) saf su ve ters misel sistemler içerisindeki durgun-hal anizotropi değerleri $\mathrm{W}_{0}$ de ğerlerinin fonksiyonu olarak Çizelge 2'de verilmiştir. Çizelgede görüldüğü gibi $\mathrm{W}_{0}$ değeri arttıkça anizotropi azalmış fakat en büyük $\mathrm{W}_{0}$ değerinde bile saf suda gözlenen değerden (-0.16) çok yüksek bir değer gözlenmiştir. $\mathrm{Bu}$ durum FL bileşiğinin saf sudaki durumuna kıyasla ters

\section{SONUÇ}

Buçalışmada,Floresinve Safranin-T molekülleri arasındaki enerji transferine organize surfaktant sistemlerin etkisi UV-Gör. absorpsiyon, durgun-hal ve zamana-bağlı floresans spektroskopisi teknikleri kullanılarak incelenmiştir. FL-ST çifti için su, ters misel ve mikro-emülsiyon çözeltiler içerisindeki enerji transfer parametreleri hesaplanmıştır. Ters misel ve mikro-emülsiyon ortamların boyutları değiştirilerek donör-akseptör arası mesafe (r)

\section{KAYNAKLAR}

Aydın BM, Acar M, Arık M and Onganer Y. 2009. The fluorescence resonance energy transfer between dye compounds in micellar media. Dyes and Pigments, 81: 156-160.

Bose D, Sarkar D, Girigoswami A, Mahata A, Ghosh D and Chattopadhyay N. 2009. Photophysics and rotational relaxation dynamics of cationic phenazinium dyes in anionic reverse micelles: Effect of methyl substitution. The Journal of Chemical Physics, 131: 114707.

Bozkurt E, Acar M, Meral K, Arık M and Onganer Y. 2012. Photoinduced interactions between coumarin 151 and colloidal CdS nanoparticles in aqueous suspension. Journal of Photochemistry and Photobiology A: Chemistry, 236: 41-47. misellerdeki su havuzlarında daha sınırlı olarak hareket ettiğini göstermektedir. $\mathrm{Bu}$ nedenle, enerji transfer olayı misel/su arayüzündeki $\mathrm{FL}$ molekülünden, su havuzunda çözünmüş akseptör molekülüne (ST) gerçekleşmektedir (Seth et al.2005). Ayrıca $r$ değerinin artması, ters misel havuzlarında bağlı suyun içerisindeki mikroçevrenin saf sudan farklı olduğunu göstermektedir (Bose et al. 2009).

ve enerji transfer verimliliği (E) gibi önemli parametrelerin kontrol edilebileceği gözlenmiştir. Ayrıca yüksek değerlerde enerji transfer verimliliğinin elde edilmesi literatürde oldukça az rastlanan sonuçlar arasında yer almaktadır. $\mathrm{Bu}$ sonuçlar enerji transferinin sıklıkla kullanıldığı 1 şık saçan diyotlar (LED), florometrik iyon sensörleri ve biyosensörler gibi birçok araştırma alanına önemli katkılar sağlayacaktır (Bozkurt et al. 2015; Min et al. 2014; Shi et al. 2015).

Bozkurt E, Arık M and Onganer Y. 2015. A novel system for $\mathrm{Fe}^{3+}$ ion detection based on fluorescence resonance energy transfer. Sensors and Actuators B: Chemical, 221: 136-147.

Bozkurt E, Bayraktutan T, Acar M and Toprak M. 2013. Spectroscopic studies on the interaction of fluorescein and safranine T in PC liposomes. Spectrochimica Acta Part A: Molecular and Biomolecular Spectroscopy, 101: 31-35.

Brouwer AM. 2011. Standards for photoluminescence quantum yield measurements in solution (IUPAC Technical Report). Pure and Applied Chemistry, 83: 2213-2228.

Chatterjee S, Nandi S and Bhattacharya S. C. 2005. Fluorescence resonance energy transfer from Fluorescein to Safranine T in solutions and in micellar medium. Journal of Photochemistry and Photobiology A: Chemistry, 173: 221-227. 
Chen Y, Chen L, Ou Y, Wang Z, Fu F and Guo L. 2016. DNAzymebased biosensor for $\mathrm{Cu}^{2+}$ ion by combining hybridization chain reaction with fluorescence resonance energy transfer technique. Talanta, 155: 245-249.

Chowdhary J and Ladanyi BM. 2009. Molecular Dynamics Simulation of Aerosol-OT Reverse Micelles. The Journal of Physical Chemistry B, 113: 15029-15039.

Clegg RM. 1992. Fluorescence resonance energy transfer and nucleic acids Methods in Enzymology Academic Press, 353388

De S and Girigoswami A. 2004. Fluorescence resonance energy transfer-a spectroscopic probe for organized surfactant media. Journal of Colloid and Interface Science, 271: 485-495.

Dey D, Saha J, Roy AD, Bhattacharjee D and Hussain SA. 2014. Development of an ion-sensor using fluorescence resonance energy transfer. Sensors and Actuators B: Chemical, 195: 382388 .

Eastoe J, Hollamby MJ and Hudson L. 2006. Recent advances in nanoparticle synthesis with reversed micelles. Advances in Colloid and Interface Science, 128-130: 5-15.

Eskici G. and Axelsen PH. 2016. The Size of a Reverse Micelle. Biophysical Journal, 110: 571a.

Ghosh D. Batuta S. Begum NA. And Mandal D. 2017. Proton transfer dynamics in a polar nanodroplet: ESIPT of 4'-n,ndimethylamino-3-hydroxyflavone in AOT/alkane/water reverse micelles. Journal of Luminescence, 184: 64-73.

Hazra P and Sarkar N. 2001. Intramolecular charge transfer processes and solvation dynamics of coumarin 490 in reverse micelles. Chemical Physics Letters, 342: 303-311.

Hillisch A, Lorenz M and Diekmann S. 2001. Recent advances in FRET: distance determination in protein-DNA complexes. Current Opinion in Structural Biology, 11: 201-207.

Kumar Das A, Mondal T, Kumar Sasmal D and Bhattacharyya K. 2011. Femtosecond study of ultrafast fluorescence resonance energy transfer in a catanionic vesicle. The Journal of Chemical Physics, 135: 074507.

Lakowicz JR. 2013. Principles of fluorescence spectroscopy: Springer Science \& Business Media.

Lee HL, Dhenadhayalan N and Lin KC. 2015. Metal ion induced fluorescence resonance energy transfer between crown ether functionalized quantum dots and rhodamine B: selectivity of $\mathrm{K}^{+}$ion. RSC Advances, 5: 4926-4933.

Mathew DS and Juang RS. 2007. Role of alcohols in the formation of inverse microemulsions and back extraction of proteins/ enzymes in a reverse micellar system. Separation and Purification Technology, 53: 199-215.

Min, X., Huang, Z., Fang, M., Liu, Y.-G., Tang, C., \& Wu, X. 2014. Energy Transfer from $\mathrm{Sm}^{3+}$ to $\mathrm{Eu}^{3+}$ in Red-Emitting Phosphor LaMgAl11O19: $\mathrm{Sm}^{3+}, \mathrm{Eu}^{3+}$ for Solar Cells and Near-Ultraviolet White Light-Emitting Diodes. Inorganic Chemistry, 53: 6060-6065.
Müller-Goymann C. 2004. Physicochemical characterization of colloidal drug delivery systems such as reverse micelles, vesicles, liquid crystals and nanoparticles for topical administration. European Journal of Pharmaceutics and Biopharmaceutics, 58: 343-356.

Ohta Y, Kamagata T, Mukai A, Takada S, Nagai T and Horikawa K. 2016. Nontrivial Effect of the Color-Exchange of a Donor/ Acceptor Pair in the Engineering of Förster Resonance Energy Transfer (FRET)-Based Indicators. ACS Chemical Biology, 11: 1816-1822.

Pileni MP. 1993. Reverse micelles as microreactors. The Journal of Physical Chemistry, 97: 6961-6973.

Rabouw, F. T., Den Hartog, S.,A., Senden, T., and Meijerink, A. 2014. Photonic effects on the forster resonance energy transfer efficiency. Nature Communications, 5: 3610-3616.

Quinlan FT, Kuther J, Tremel W., Knoll W, Risbud S and Stroeve P. 2000. Reverse micelle synthesis and characterization of $\mathrm{ZnSe}$ nanoparticles. Langmuir, 16: 4049-4051.

Seth D, Chakrabarty D, Chakraborty A and Sarkar N. 2005. Study of energy transfer from 7-amino coumarin donors to rhodamine $6 \mathrm{G}$ acceptor in non-aqueous reverse micelles. Chemical Physics Letters, 401: 546-552.

Shi, J., Chan, C., Pang, Y., Ye, W., Tian, F., Lyu, J., Zhang, Y., Yang, M. 2015. A fluorescence resonance energy transfer (FRET) biosensor based on graphene quantum dots (GQDs) and gold nanoparticles (AuNPs) for the detection of mecA gene sequence of Staphylococcus aureus. Biosensors and Bioelectronics, 67: 595-600.

Sundström V, Pullerits T and Van Grondelle R. 1999. Photosynthetic Light-Harvesting: Reconciling Dynamics and Structure of Purple Bacterial LH2 Reveals Function of Photosynthetic Unit. The Journal of Physical Chemistry B, 103: 2327-2346.

Tan A, Bozkurt E, Kishali N and Kara Y. 2014. A New and Convenient Synthesis of Amino-phthalimide (1H-Isoindole-1, 3 (2H)-dione) Derivatives and Their Photoluminescent Properties. Helvetica Chimica Acta, 97: 1107-1114.

Wang J, Wei J, Su S and Qiu J. 2015. Novel fluorescence resonance energy transfer optical sensors for vitamin B12 detection using thermally reduced carbon dots. New Journal of Chemistry, 39: 501-507.

Wang Y, Lee CH, Tang YL and Kan CW. 2016. Dyeing cotton in alkane solvent using polyethylene glycol-based reverse micelle as reactive dye carrier. Cellulose, 23: 965-980. 